\title{
Role of Infection in Neurologic and Psychiatric Diseases
}

\author{
Marylou V. Solbrig ${ }^{1}$ and Guey Chuen Perng ${ }^{2}$ \\ ${ }^{1}$ Department of Medicine (Neurology) and Medical Microbiology, Health Science Center, University of Manitoba, \\ Winnipeg, Manitoba, Canada R3A 1 R9 \\ ${ }^{2}$ Department of Pathology and Laboratory Medicine, Emory Vaccine Center, Emory University School of Medicine, \\ Atlanta, GA 30322, USA
}

Correspondence should be addressed to Marylou V. Solbrig, msolbrig@uci.edu

Received 7 April 2010; Accepted 7 April 2010

Copyright () 2010 M. V. Solbrig and G. C. Perng. This is an open access article distributed under the Creative Commons Attribution License, which permits unrestricted use, distribution, and reproduction in any medium, provided the original work is properly cited.

What makes CNS injury by pathogens different from other CNS afflictions such as stroke or Alzheimer's Disease is well illustrated in the manuscripts of this volume. We will see that viral, bacterial, or prion-induced injuries are dynamic and varied. No two infection cases are the same due to host or agent factors. We will encounter pathogens that are shared with other species and some that range across the globe. We will also find robust examples of gene $\mathrm{x}$ age $\mathrm{x}$ environment interactions as determinants of nervous system disease, which can be incorporated into understanding many neurobiological processes.

The role of infection in neurologic and psychiatric diseases is predicated on clinical and research observations, which have been expanded into the domains of neurobiology by hypotheses from several perspectives. Our collected papers come from perspectives of epidemiology, protein biochemistry, immunology, genetics, molecular biology, pathology, behavioral sciences, psychology, neuropharmacology, and human and veterinary medicine. These articles are comprehensive reviews, topical summaries, or original research papers.

We hope that this collection of manuscripts provides a greater understanding of both familiar and unfamiliar pathogens, prompts new ideas on disease mechanisms and treatments, and stimulates further cooperative work on infection in neurologic and psychiatric diseases.

We thank our contributors from around the world. When it comes to transmissible diseases, the world is a small place. Although we did not specifically solicit for public health topics, we note that cross-species transfers, emerging diseases, epidemics and pandemics, are developed as key discussions in several of our manuscripts. For this reason we dedicate this special issue to the One Health Initiative, whose work is defined by the Mission Statement on their website: www.onehealthinitiative.com/mission.php "Recognizing that human and animal health and mental health.... are inextricably linked, One Health seeks to promote, improve, and defend the health and well-being of all species by enhancing cooperation and collaboration between physicians, veterinarians, and other scientific professionals...."

We express our sincere gratitude to all authors and reviewers for their time and effort, to Betsy Foxman, Editor-in-Chief for the invitation, and the staff at Hindawi Publishing for their assistance and support.

Marylou V. Solbrig Guey Chuen Perng 


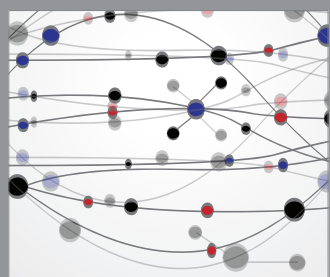

The Scientific World Journal
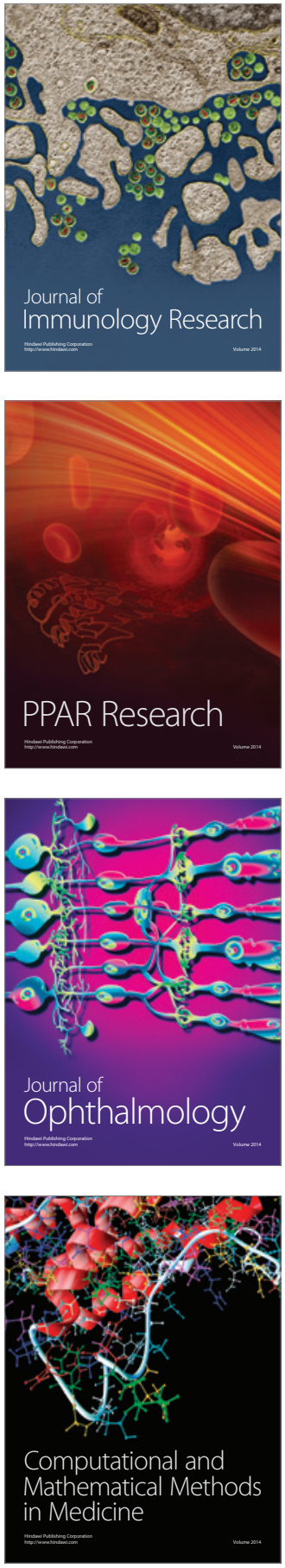

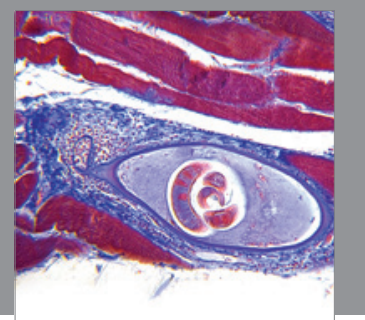

Gastroenterology

Research and Practice
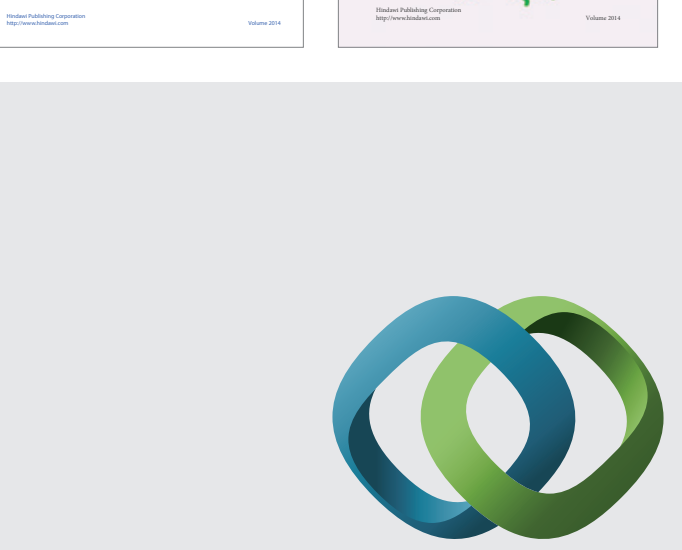

\section{Hindawi}

Submit your manuscripts at

http://www.hindawi.com
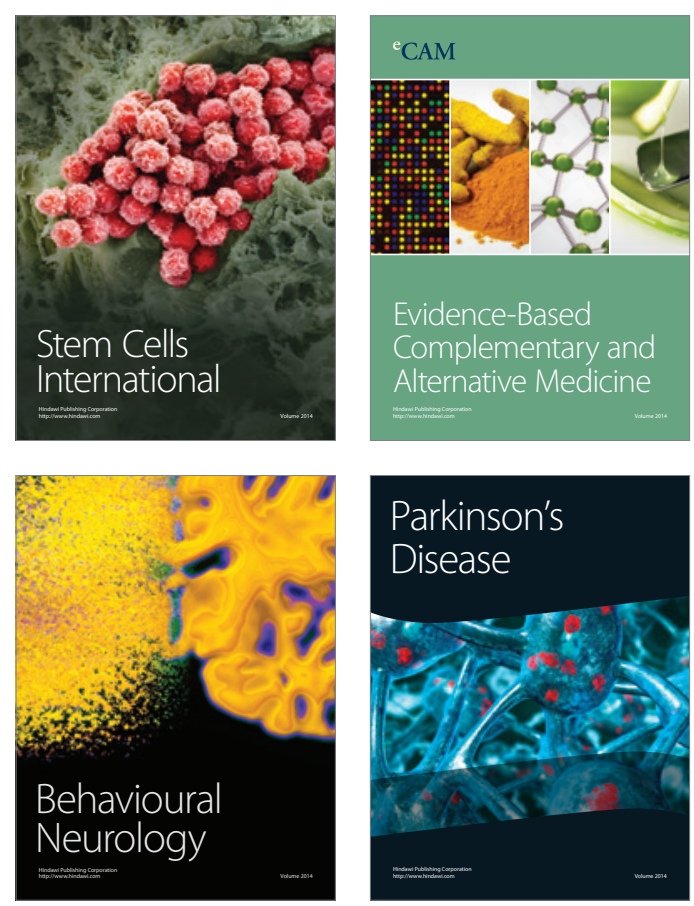

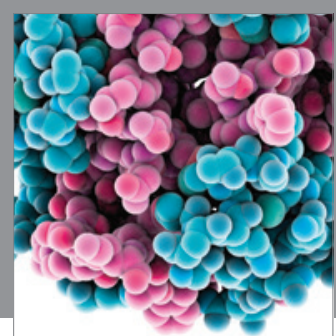

Journal of
Diabetes Research

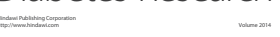

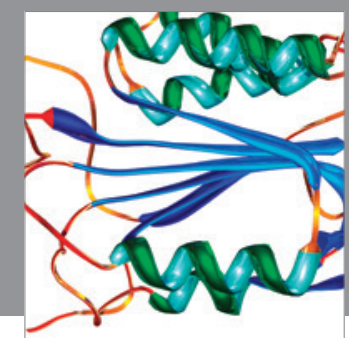

Disease Markers
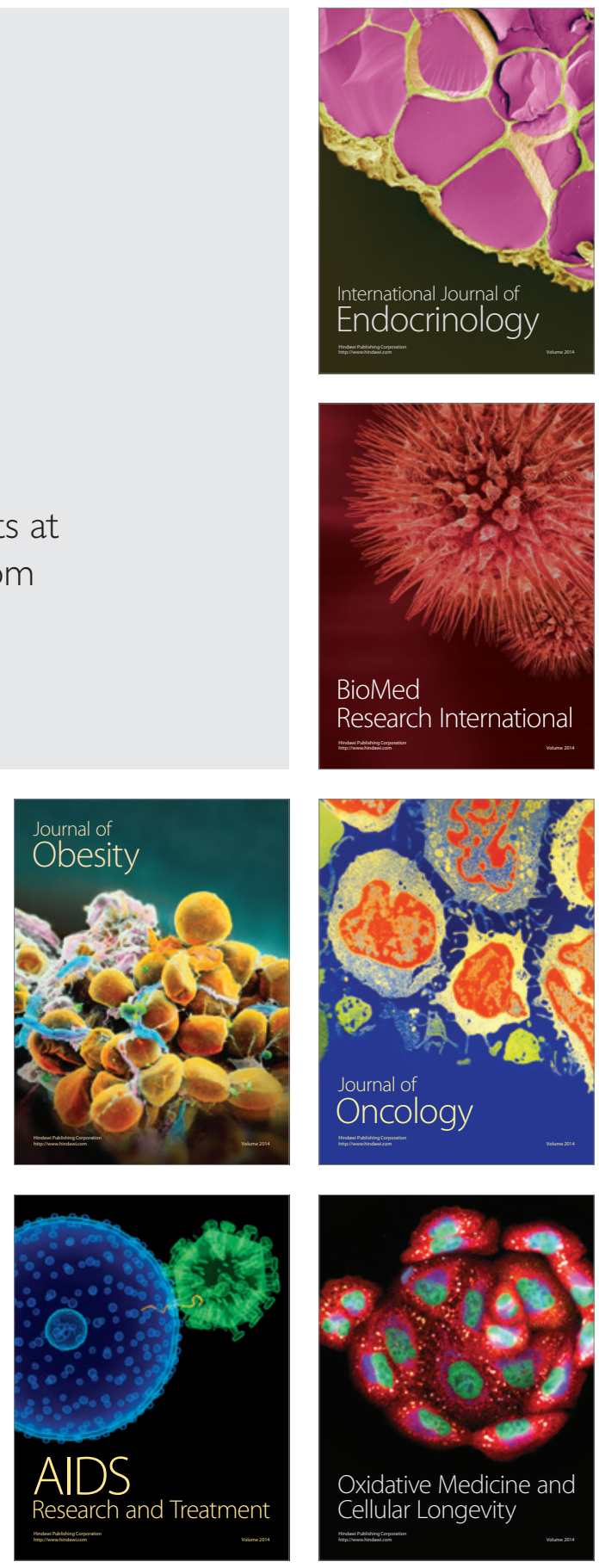